\title{
The Norwegian Television Market in the 1990s
}

\author{
Legal Framework, Market Situation, Financial Information and \\ Programming of Public and Private Television
}

\author{
Trine Syvertsen \& Gro Maren Mogstad Karlsen
}

\section{Introduction}

The Norwegian television market has been completely transformed in the 1990s. New technology, along with political and economic liberalisation, has led to increased competition for talent, programmes, audiences and revenue. At the same time, the global processes of concentration, globalisation and convergence are changing the overall framework within which the broadcasters operate. So far, the competition has been most intense between national operators, but there is an increased presence of large transnational companies in the Norwegian market.

In this report, the aim is to identify and discuss key features of the television market as it has evolved throughout the 1990s. The report is based on a study originally commissioned by the European research agency PROGNOS on behalf of the European Commission. The purpose of the study was to supply the competition authorities (DGIV) of the Commission with market analysis relevant for competition policy. Much of the data and several of the calculations included in the original report has been omitted in this version, mostly for reasons of confidentiality. In the present report, the key focus is the differences between national television operators. What are the legally defined privileges and obligations of each channel? What

Department of Media and Communication, University of Oslo, P.O.Box 1093, Blindern, NO-0317 Oslo,

trine.syvertsen@media.uio.no

g.m.m.karlsen@media.uio.no are the financial resources available to them? And how does this correspond with the programming they put out?

Thus, the main aim of the report is to present information about the Norwegian situation that is not readily available - especially not in English. In addition, the report contributes to the ongoing discussion about the broadcasting situation in small European countries. Norway is not a member of the European Union (a majority of the population voted "no" both in 1972 and 1994), but is still, as a member of the European Economic Area (EEA), obliged by the EU legal framework for broadcasting. In recent years, the European Union, and to some degree also national governments, have moved away from traditional forms of broadcasting legislation, based on cultural policy, towards a situation where broadcasting is perceived more as a business. This situation poses challenges to public broadcasting institutions, whose privileges are increasingly contested by the private operators. It also poses interesting challenges to media researchers, who traditionally have been most interested in the cultural and political aspects of broadcasting. In the new situation, economic data and economic analysis will be increasingly relevant in order to understand how broadcasting institutions operate.

\section{Public and Private \\ Television Channels - an Overview}

The emphasis in the report is on the main national channels - NRK1, NRK2, TV2, TVNorge - but significant information is also included regarding TV3 and pay-TV-channels available in Norway. Key 
characteristics of the main Norwegian channels are as follows:

\section{NRK1:}

- Established in 1933, television service from 1960.

- Licence fee funded, state owned company, public service obligations.

\section{NRK2:}

- Began broadcasting in 1996. Specialised channel (youth \& culture), operated jointly with NRK1

- Licence fee funded, state owned company, public service obligations.

TV2:

- Established in 1991, began broadcasting in 1992.

- Advertisement funded, privately owned channel, public service obligations.

\section{TVNorge:}

- Established and began broadcasting in 1988. Originated as a local television channel. Some co-ordination with TV2 from 1997.

- Advertisement funded, privately owned, no public service obligations.

\section{TV3-Norway:}

- Established and began broadcasting in 1987. Transmitting from the United Kingdom, operates outside Norwegian legislation.

- Advertisement funded, privately owned channel. Part of a pan-Scandinavian multi-channel operation.

\section{Chapter Outline.}

\section{Sources. Division of Labour}

The report has four principal parts. In part I the aim is to identify the differences in privileges and obligations between private and public channels through a discussion of legislation and practice. In part II the key characteristics of the competitive situation is outlined: market shares, distribution of advertising revenue, competition for rights and talent etc. Part III contains financial information and discuss the television companies as economic operators. In part IV the main differences in programming are discussed. The final part outlines current trends and issues, particularly regarding digitalisation and convergence.

The report is based on documentary analysis and interviews. Most of the interviews were carried out during the spring and summer months of 1998 . We are grateful to sources in the television companies and elsewhere who provided information, some even during their holidays. A list of sources appear at the end of the report. The original report was completed in August 1998 and contained information for the period 1993/94-1997. Most tables have later been updated with information for 1998 .

Research assistant Gro Maren Mogstad Karlsen has collected most of the empirical evidence for the report. She has conducted almost all the interviews, collected most of the market data and contributed to the analysis and discussion. Most of the actual text has been put together by Trine Syvertsen. We are also grateful to Terje Solsvik, financial journalist, who has contributed to the analysis of the capital structure of various companies. Finally, we wish to thank Josef Trappel of PROGNOS, who constructed the original resarch design and made many valuable comments along the way.

\section{Legal Framework. Privileges and Obligations of Various Channels}

\section{General Information about the Regulation of Television in Norway}

Television in Norway is regulated by the Broadcasting Act (Kringkastingsloven), supplementary regulations issued by the Ministry of Culture (forskrifter) and licence agreements (konsesjonsbestemmelser). As an EEA member, Norway is bound by the EU Television Directive, and its clauses are incorporated into the Broadcasting Act and the supplementary regulations. In some cases, which will be indicated below, the Norwegian regulations are stricter than those of the EU Television Directive. EU permits individual countries to have stricter regulations for their national operators as long as they permit companies who obey the Directive to broadcast within their borders.

Broadcasting regulation in Norway is rather fragmented, and there is no single, specialised agency responsible for television regulation. The Mass Media Authority (Statens medieforvaltning) is responsible for local television, press subsidies and advertising/sponsorship regulations, whereas the question of whether or not the various channels fulfil their obligations, is determined by Parliament 
and the Ministry of Culture. Another body that has influenced media regulation in later years is the Public Broadcasting Council (Allmennkringkastingsrådet). The Council was established 1996 in order to advice the government on whether or not the public service channels fulfil their obligations.

The television market as a whole is to some degree regulated by the Norwegian Competition Authority (Konkurransetilsynet). In 1998, a new body, the Media Ownership Authority (Eierskapstilsynet) was set up to monitor concentration and mergers in the media business. In 1999 a Media Ownership Act was put into practice, replacing some of the previous restrictions on ownership in the media business. The purpose of the Act is to secure freedom of speech, the actual possibilities for expression and a versatile media scene within press and broadcasting. The Media Ownership Authority can stop take-overs or a broadcasting company buying shares in another broadcasting company when the operator, alone or in co-operation with others, have a significant position in the national, regional or local media market, and this is in violation with the purpose of the Act.

Although there is a comprehensive framework of broadcasting regulation, many of the expectations levelled towards the television institutions cannot be found in the legal framework. Historically, Norwegian broadcasting have been regulated through general guidelines, rather than through detailed specifications of rights and duties, and the policy style has been consensual and incremental with a preference for self-regulation. The obligations of both NRK and TV2 are, consequently, less specific than in many other countries, and it is necessary to look to a wide range of sources in order to understand how these obligations are interpreted. The most relevant documents are the annual government white papers on the media situation, specific conditions laid down in the annual budget debates when the level of the licence fee is set (NRK) and conditions put forward when new services are established (such as TV2 and NRK2).

\section{The Right to Broadcast}

The Broadcasting Act $\S 2-1$ grants the NRK the right to be a broadcaster; all other services broadcasting from Norway needs a licence. Licences are issued by the Ministry of Culture, they are usually limited in time and may be linked with specific obligations determined by the Ministry. Until 1988, a licence was also necessary to re-transmit satellite broadcasting from abroad.
Any television company established within the constitutional area of the Broadcasting Act is obliged to abide by Norwegian regulations (supplementary regulations $\S 1-1$ ). This is interpreted to mean that the company's actual economic activities are carried out within Norwegian borders. There are disagreements as to the interpretation of this in the case of TV3. TV3 broadcasts from the UK, but does have an organisation in Norway that sells advertising. The transactions are nevertheless invoiced from London, so that it is difficult to determine where the "actual economic activities" of the organisation takes place. Despite sustained efforts, Norwegian authorities have not succeeded in making TV3 comply with Norwegian law.

\section{Advertising and Sponsorship Regulations}

The regulation of advertising and sponsorship is more specific than the general regulation of broadcasting. The total amount of advertising is regulated, both regarding the total share and the share in any given hour. Further regulations relate to the language used in advertising, when it is forbidden to transmit advertising and which products that can not be advertised on television.

The Broadcasting Act and the supplementary regulations contain the same rules regarding sponsorship and advertising as the EU television Directive 97/36/EC and 89/552/EEC. On some points, however, the Norwegian regulations are stricter than the European ones. The supplementary regulations to the Broadcasting Act sets a maximum limit of $15 \%$ advertising per day and $20 \%$ per hour, which is in line with European regulations. The supplementary regulations further states that advertising shall be transmitted in blocks between programmes, whereas the EU Directive (and the Norwegian Broadcasting Act § 3-2 ) states that they should mainly be transmitted in blocks.

News, current affairs, documentaries and religious programmes cannot be interrupted by advertising breaks. Specific regulations apply to the interruption of plays, concerts and sports events (only "natural breaks"). If a feature film or TV film is interrupted, advertising can be transmitted if the interruption lasts more than 20 minutes. Both TV2 and TVNorge use a system whereby they interrupt feature films with two advertising blocks and a news broadcast. Advertising directed at children and teenagers under 18 years is prohibited, and there is a ten minute ban on advertising before and after children's programmes. The supplementary regulations are specific on what constitutes "child- 
ren's programmes". Sponsorship of programmes for children and young people is prohibited.

Advertising should mainly be in Norwegian or other languages that the channel uses in their home-produced programmes. There is a ban on religious and political advertising (political advertising is permitted in radio), as well as advertising for weapons and toy guns etc. On certain holidays (4 days a year), advertising is prohibited.

Sponsorship is permitted to a certain extent. Sponsors shall be identified with posters at the beginning and end of each programme. There are specific regulations as to how long the posters should be shown and what they should contain. Here the rules have been liberalised in recent years. Currently it is legal for a specific brand name to sponsor a programme, whereas previously, only the company could be the sponsor (and only their logo could be shown). Producers of goods that cannot be advertised on television, cannot be sponsors. Product placement is prohibited, defined as a ban on the encouragement to purchase services of goods within programmes. Presentations of prizes in quiz programmes etc. are regulated separately. Special regulations apply to the NRK's use of sponsorship (see below).

\section{NRK: Formal Regulations}

The NRK is regulated through a specific chapter in the Broadcasting Act. The Act states that the purpose of the NRK is to carry on public service broadcasting and engage in activities in connection with broadcasting ( $§ 6-1$ ). "Public service broadcasting" is not defined, neither in the Act nor in the supplementary regulations, but interpretations can be found in NRK's statutes and other political documents (see below).

Originally, the NRK was state-owned, and Government and Parliament exercised quite detailed control over organisational and financial matters. In 1988 the NRK was made a public foundation, and in 1996 it was made a limited company. This last move granted the NRK board the right to appoint the Director-General and establish new services without going through a lengthy political process. It also made it easier for the corporation to engage in commercial spin-off activities, although not easy enough according to the NRK. In 1998 NRK asked for a further liberalisation of the framework guiding its commercial activities. Most notably, NRK wants the opportunity to engage in other activities than broadcasting and to fund potential new channels with advertising. NRK has also asked that only issues of "significant importance for society" need to be discussed with the general assembly (Minister of Culture). These proposals have yet to be debated in Parliament, but the Ministry has declared its support.

The Broadcasting Act states that the NRK should be organised as a limited company where the State holds all the shares. The regulations concerning shareholding companies [Lov om aksjeselskaper] applies to the NRK, unless otherwise specified in the Broadcasting Act (§ 6-1). The Minister of Culture is the General Assembly of the NRK. The Broadcasting Act (§ 6-3) states that the Director-general is the top executive with responsibility for both programming and administrative matters.

The Broadcasting Act § 6-4 states that the NRK shall be funded through a licence fee and sales and that the NRK cannot be funded through advertising. The level of the fee is determined annually by Parliament. Since 1948 the NRK has collected its own revenue and determined the specific conditions upon which a licence could be obtained. The current licence fee is a combined fee for radio and television that is collected by the NRK. Until 1994 a second main source of NRK revenue was a duty that was added to the prices of all sets (ca. 15\%) and went directly to the NRK. The NRK was compensated by a higher licence fee when it lost this source of revenue.

There is no ban on the NRK accepting sponsorship, although the issue is rather controversial. NRK is defending its right to sponsorship income against politicians and other critics who see this as a sign of commercialisation. TV2 claims that NRK is attracting sponsorship revenue which, in principle, should be reserved for commercial channels. In 1995 , a sponsorship limit was set as to $1 \%$ of the total operating income of the corporation. This rule has turned out to be difficult to enforce, and in 1999, the government proposed that sponsorship should instead be restricted to certain categories of programming.

A Broadcasting Council is appointed by the Government and Parliament (Broadcasting Act § 71). The mandate of the Council is to discuss NRK's programming and related issues. The Council has advisory powers only. There are also regional advisory councils whose task it is to advice NRK's regional offices.

Norwegian cable companies are obliged to transmit NRK1 and 2.

From late 1996, when the NRK became a limited company, its objects were further specified in a separate set of regulations (Vedtekter for NRK a/s). 
These state that the NRK should have a board of nine members: six appointed by the Minister of Culture and three elected among the employees of the corporation. These regulations also, for the first time in NRK's history, define the purposes of the corporation in some detail (official NRK translation):

\section{§ 3 The Purposes of the Company}

NRK is a public service radio and TV company carrying on radio and TV broadcasting and activities in connection with broadcasting. Through its national, regional and local programme activities NRK shall:

1. Consistently promote freedom of expression and information, basic democratic values and fundamental human rights and values. Its programming should be characterised by balance, impartiality, objectivity and concentration on the essentials.

2. Support democracy through a varied range of news, facts, commentary and debate on social issues, including for minorities and special groups.

3. Support, create and develop Norwegian culture, art and entertainment.

4. Attach importance to the educational nature of programming and broadcast philosophical and religious programmes.

5. Produce and broadcast quality programmes for children and young people.

6. Promote the use and respect for the Norwegian language and ensure that the two forms of language are represented by at least $25 \%$ of voice broadcasts on radio and television and in NRK's information activities.

7. Help to safeguard and develop Sámi language and culture.

8. Broadcast programmes for ethnic and linguistic minorities.

With General Assembly Consent, NRK may establish daughter companies and participate in other companies carrying on other types of activities than public service broadcasting.

\section{NRK: Interpretations and Definitions}

The NRK has always had a large degree of editorial and operational autonomy, but this autonomy was by the very nature of the broadcasting structure qualified: it was commonly accepted that the broadcasters should fulfil a range of duties in return for their privileged position. Until 1988, when the NRK became a public foundation, the duties were specified in the detailed financial and administrative decisions Parliament and Government made on behalf of the corporation. In recent years, and especially after the NRK became a limited company in 1996, interpretations of the obligations are specified in more general media policy documents. The media white paper presented in 1993 states accordingly:

Throughout the NRK's history, a fundamental principle has been that Governments do not interfere in programming.... When it comes to the question of what programming policy the NRK should adopt in competition with other channels, parliament has on several occasions presented the NRK with clear indications as to what it should perceive as its main challenges (St. meld. 32: 1992-93:131) (our translation and emphasis)

Historically, the NRK have been expected to fulfil three main obligations: provide a universal service, present a balance and diverse programme output, and serve the national interest (Syvertsen 1992). Although the situation has changed, these obligations still provide a framework for the discussion of NRK's duties today. When NRK2 was established, for example, it was on the explicit condition that its transmission network should be extended towards national coverage as soon as possible. In order to serve the nation, the NRK is also expected to ensure that more than $50 \%$ of its programming is of Norwegian origin, although no formal obligation exist.

Nevertheless, in recent years, it is the obligation of the NRK towards diversity that have cause the most controversy. Since 1985, various media policy documents have instructed the corporation to "remain distinctive" and not to follow the priorities of the advertising-funded channels (see, for example, St.meld 32, 1992-93:132). Under this obligation, NRK has been instructed to take a special responsibility for some genres: news, current affairs and documentaries; cultural, educational and religious programming; programming reflecting Norwegian life and identity; Norwegian classic and modern drama; quality programming for children and young people, and programmes for social and ethnic minorities. The responsibility of the NRK to provide high quality programming within these genres is 
regularly mentioned in political documents (see, for example, St. meld. 32 1992-93: 131-132, St. meld. 42 1993-94: 11), as well as in the special regulations (above).

Although the NRK's responsibility for informational and cultural programming is strongly emphasised in these documents, NRK has not been instructed to limit itself to the type of programmes that its competitors do not provide. On the contrary, it is regularly stressed that NRK should transmit programmes appealing to a mass audience. As it is stated in the 1993 media white paper: "It is absolutely clear that the NRK output must have a broad appeal" (St. meld. 32 1992-93: 132).

The obligation of the NRK to present news and current affairs in an impartial manner has been important throughout its history. In 1975, in response to external criticism, the NRK Director-General defined a set of internal programme guidelines: Principles for programming (NRK's programregler) This document has been revised on several occasions and still provide the most authoritative interpretation of NRK's obligations - as NRK itself perceives them.

A final duty of the NRK, which is not made explicit in the formal regulation, is the duty to develop regional programming. In 1995, 1996 and 1997 a proportion of the licence fee was earmarked for the establishment of regional television news and by 1998 , nine regional news services were established. NRK is also instructed, in various political documents, to include more regional programming in its national services.

Generally, there is a broad consensus that the NRK should continue as a licence fee funded broadcaster, owned by the state, with a varied and broad profile. However, one of the major political parties, Fremskrittspartiet (right-wing-liberals) has, on several occasions, proposed that the NRK be sold out or reorganised as a pay-channel. Current financial difficulties have led to claims that the NRK should cease competing against the commercial companies for sports and entertainment and concentrate on "serious" programming, but this is view has not gained support in the major political parties. The debate continues, however, over the NRK's use of sponsorship money.

\section{TV2: Formal Regulations}

TV2 is regulated by the Broadcasting Act and the licence agreement (konsesjonsavtale). The most specific regulations are to be found in the latter document. The licence agreement grants TV2 the right to operate a commercial television service through terrestrial and satellite distribution. The licence states that TV2 should rent transmission capacity from Telenor (later Norkring). Universal access is stated as a long term goal (defined as at least $86 \%$ by the end of the licence period). Norwegian cable companies are obliged to transmit TV2.

The licence period is ten years, and the licence expires 31.12.2002. The licence agreement states that renewal is to be expected, but there is no guarantee. Even if the licence is renewed, the obligations may be changed. The licence agreement states that the Ministry of Culture will decide upon renewal when there are 9 months left of the licence period, but TV2 has asked that the issue is determined as soon as possible.

TV2 is established as a limited company. The original licence set a maximum limit per shareholder of $20 \%$ (later changed to $33 \%$ ) of the shares, but these limitations were removed when the Media Ownership Act was put into practice. NRK cannot own shares in TV2.

The licence agreement also specifies the source of revenue for the TV2. TV2 shall be funded through advertising, possibly in combination with pay-TV-revenue. No public funds are available for the establishment or operations of TV2, but TV2 can apply for money from production funds supported by the state.

The licence obliges the TV2 to be headquartered in Bergen, the second largest city of Norway. TV2 has a second office in Oslo and the news operation is split between the two cities. The dual structure and the location outside the capital imply substantial additional costs for the company. TV2 is obliged to establish a news and current affairs department and produce news and current affairs. All other programming should be commissioned or bought from external producers. The licence states that TV2 is obliged to reach a level of $50 \%$ Norwegian-produced material within 8-9 years.

The licence agreement states that TV2's programming shall be based on "public service principles". These are defined to be (para. 6) (our translation):

1. Universal access as a long term goal.

2. A wide range of programming, programmes for both large and small groups of viewers, including the Sámi population and minority audiences.

3. Daily news broadcasts.

4. The programmes should be aimed at strengthening Norwegian language, identity and culture.

5. Editorial independence. 
Originally, the supplementary regulations to the Broadcasting Act obliged TV2 to keep an Advisory Council with members appointed by the State. This obligation was removed in 1998.

\section{TV2: Interpretations and Definitions}

The obligations of TV2 are rather vague, and also in this case, it is necessary to look to other sources for interpretation. One source is the political documents upon which the decision to establish TV2 was based; documents which are mentioned in the licence agreement. These documents state that TV2 was to act as an alternative to the NRK, but also to function as a "counter-force to commercial channels". The expectation was that TV2 would produce high quality programming within a range of genres, stimulate regional production companies and reflect life in local and national communities. Like NRK, TV2 was expected to serve the whole country with a wide variety of programmes and genres (Ot.prp.55, 1989-90). In its application for the licence, TV2 endorsed these obligations.

Throughout TV2's early years, Parliament and the Ministry of Culture expressed satisfaction with TV2's fulfilment of its obligations. The authorities have continued be satisfied on some counts: most notably the extensive distribution network (which reached $96 \%$ in 1998), the high percentage of news and current affairs in the output, and the substantial share of Norwegian produced programming. For the first time in 1994, however, dissatisfaction was expressed regarding TV2's interpretations of its obligations towards diversity, minorities, and the strengthening of national identity and culture (St.meld.42 1993-94). According to recent media white papers, TV2 do no fulfil its duties properly with respect to children's programmes, serious drama, cultural programmes, music, programming for the sámi population and other minorities (St. meld. 62 1996-97, St.meld. 12 1998/99). A parliamentary majority has warned TV2 that fulfilment of the obligations is a necessary precondition for the renewal of its license (B. innst.S. nr.2 199697).

Despite all this, TV2 is not expected to be "as much public service" as the NRK. Political documents frequently refer to the "special position" of the NRK as the principal instrument of public service broadcasting. For example, the proposal to turn NRK into a limited company in 1995, stated that:

Experiences from other countries, and from TV2 operations so far, indicate that advertisement- funded public service channels will never provide the variety and quality which is available through licence-fee funded channels (Ot. prp. 69 1994-95: 1).

As TV2 has indicated that it is ready to begin negotiations for the new licence period, the debate over whether or not it is fulfilling its obligations, has intensified. It seems likely that some changes will be made when the current licence expires in 2002. An alternative which has been discussed is that TV2 should pay a fee for its licence privileges, which it does not do today. Its obligations may also be specified in more detail.

\section{TVNorge: Regulations}

TVNorge operates under a temporary licence from the Ministry of Culture (dated 08.05.1990), where it is stated that the channel is allowed to transmit satellite broadcasting from Norwegian territory. The licence is a strictly formal affair, granted to anyone who wishes to operate a satellite service. TVNorge has no public service obligations. The channel has, nevertheless, been subject to regulation by the Competition Authorities and the Media Ownership Authorities over its relationship with TV2.

In 1997, TV2 bought a 49\% share in TV2, and in September the same year, the two companies agreed that TV2 would be responsible for programming on TVNorge. The agreement between TV Norge and TV2 was very controversial, both advertisers and production companies protested and claimed that the deal in effect secured TV2 a monopoly position in the television market. The Norwegian Competition Authorities accepted the deal, despite the fact that it violated Norwegian competition law, but declared its intention to continue surveying the position of the two companies in various markets (Konkurransetilsynets vedtak 20.10.97). When TV2 begun to produce the news on TVNorge in 1998, the Ministry of Culture determined that editorial responsibility was to stay in TVNorge's hands.

In 1999, the Media Ownership Authority discussed whether TV2's ownership of $49 \%$ of TVNorge and the agreement between the two companies was in violation of the 1999 Media Ownership Act. Due to the fact that the agreement was temporary and that it could be terminated on certain conditions, the agreement was not deemed illegal according to Act. Another factor was that TV2 had committed itself to raising TVNorge's market 
Table 1. Privileges of National Channels

\begin{tabular}{|c|c|c|c|}
\hline & NRK & TV2 & Other \\
\hline $\begin{array}{l}\text { Monopoly } \\
\text { privilege }\end{array}$ & $\begin{array}{l}\text { Monopoly on licence } \\
\text { fee funding }\end{array}$ & $\begin{array}{l}\text { Monopoly on terrestrial } \\
\text { commercial TV }\end{array}$ & None \\
\hline $\begin{array}{l}\text { Financial } \\
\text { privilege }\end{array}$ & $\begin{array}{l}\text { No payment for the } \\
\text { right to broadcast }\end{array}$ & $\begin{array}{l}\text { No payment for the } \\
\text { right to broadcast }\end{array}$ & None \\
\hline $\begin{array}{l}\text { Distribution } \\
\text { privilege }\end{array}$ & $\begin{array}{l}\text { Cable companies } \\
\text { are obliged to transmit } \\
\text { NRK1 and } 2\end{array}$ & $\begin{array}{l}\text { Cable companies are } \\
\text { obliged to transmit TV2 }\end{array}$ & None \\
\hline $\begin{array}{l}\text { Other } \\
\text { privileges }\end{array}$ & $\begin{array}{l}\text { The only broadcaster } \\
\text { that does not need a } \\
\text { licence }\end{array}$ & & None \\
\hline
\end{tabular}

Table 2. Obligations of National Channels

\begin{tabular}{|c|c|c|c|}
\hline & NRK & TV2 & Other \\
\hline $\begin{array}{l}\text { Programme } \\
\text { obligations }\end{array}$ & $\begin{array}{l}\text { Public service broadcasting. } \\
\text { Both mass audience and } \\
\text { minority programming. } \\
\text { Special responsibility for } \\
\text { certain genres. } \\
\text { Remain distinctive from } \\
\text { commercial services. }\end{array}$ & $\begin{array}{l}\text { Public service broadcasting. } \\
\text { Programmes for large and } \\
\text { small groups of viewers. } \\
\text { Be an alternative to both } \\
\text { NRK and other commercial } \\
\text { services. }\end{array}$ & None \\
\hline $\begin{array}{l}\text { Distribution } \\
\text { requirements }\end{array}$ & $\begin{array}{l}\text { NRK1 expected to reach all. } \\
\text { NRK2 expected to reach } \\
\text { minimum } 80 \% \text {. }\end{array}$ & $\begin{array}{l}\text { Obliged to reach at least } \\
86 \% \text { of the population. }\end{array}$ & None \\
\hline $\begin{array}{l}\text { Advertising and } \\
\text { sponsorship } \\
\text { restrictions }\end{array}$ & $\begin{array}{l}\text { No advertising on main } \\
\text { services. Specific } \\
\text { sponsorship restrictions. }\end{array}$ & $\begin{array}{l}\text { Some restrictions on } \\
\text { advertising and sponsorship. }\end{array}$ & $\begin{array}{l}\text { Some restrictions on } \\
\text { advertising and } \\
\text { sponsorship. }\end{array}$ \\
\hline $\begin{array}{l}\text { Production } \\
\text { requirements }\end{array}$ & $\begin{array}{l}\text { Obliged to produce regional } \\
\text { and minority programming. }\end{array}$ & $\begin{array}{l}\text { Obliged to commission all } \\
\text { progs., apart from news and } \\
\text { current affairs, from external } \\
\text { producers. } \\
\text { Headquarters in Bergen. }\end{array}$ & None \\
\hline
\end{tabular}

shares, and would have to pay compensation is this was not achieved. The Media Ownership Authority has, nevertheless, prevented TV2 from buying the remaining $51 \%$ shares in TVNorge. The Authority claims that this violates media Ownership Act, but this decision is contested by TV2 (see Part III for a discussion of the agreement between TV2 and TVNorge.)

\section{TV3: Regulations}

TV3 operates from London and is subject to the regulations of the British Independent Television
Commission, a fact that allows the channel more liberal advertising regulations than those which apply to Norwegian channels. After sustained attempts to make TV3 comply with Norwegian law, Norwegian authorities have resigned and accepted that TV3 is outside their jurisdiction. Recently, they have launched their complaints at ITC rather than at TV3. TV3, on their part, argues that British regulations, in many cases, are more specific and stricter than the Norwegian ones. According to TV3, complaints from the Norwegian Mass Media Authority have not resulted in any financial sanctions from ITC. 


\section{Pay-TV and Digital Packages}

Pay-TV and digital television packages, such as Canal Digital, do not need a licence to operate. Canal Digital is a distributor only, offering packages of already existing channels. It has no licence agreement and no editorial responsibility for the content that is transmitted.

\section{Summary: Privileges and Obligations of Public and Private Channels}

The privileges and obligations of the national channels are summarised in two tables (Table 1 and Table 2). In addition to the obligations specified here, all channels are expected to obey by the minimum regulations set out in the EU television directive.

\section{Market Analysis General Features of the Market}

The Norwegian television market is small and has certain features which makes terrestrial broadcasting costly and difficult. Norway has a population of only 4.2 million, there is on average 13 inhabitants pr. square $\mathrm{km}$., and large parts of the country is uninhabitable. Traditionally, newspaper reading has been high in Norway, and so is the total number of newspapers (220 in 1997). In later years, the growth in the use of Internet has been rapid: in November $1997,8 \%$ had used the Internet on an average day rising to $22 \%$ two years later (Futsæter 1998, Gallup 1999). Norway is in 1999 the second country in the world (after Finland) when it comes to Internet use per capita. The time spent watching television, on the other hand, is relatively low com- pared to many other countries. Between 1993 and 1998 the average viewing time per person 12 years and over increased from 133 minutes to $151 \mathrm{~min}$ utes per day. This is similar to the situation in the other Nordic countries (Nordicom 1999), but these countries still remain low in television usage compared to the rest of the developed world.

\section{Access to Television Channels. Market Shares}

More than every other household in Norway have access to international and other services through satellite or cable. Of the 1.7 million households, around $38 \%$ had access to cable and $20 \%$ had satellite dishes by the end of 1998. Cable is about to reach saturation point, but massive growth is currently taking place in the sale of dishes.

Of the national channels, NRK is most widely available. By the end of 1998, 100\% of the population could receive NRK1, 96\% could receive TV2, $77 \%$ could receive NRK2 and $61 \%$ TV3. TVNorge is increasing its distribution rapidly through co-operation with local television stations and could be received by $82 \%$ by the end of 1998 .

TV2 has struggled to win viewers from the previously established channels. Both TVNorge and TV3 had obtained solid positions before TV2 came, and fought hard to sustain their market shares. NRK lost more, but still defended its market position well compared with public television stations in many other countries. Recently, both NRK1 and TV2 have begun to loose viewers to newer and more specialist channels. As such channels become more widely available there are clear indications that the television consumption market is fragmenting (Table 3).

Table 3. Market Shares Television. Total Television Population

\begin{tabular}{lrrrrrr} 
& 1993 & 1994 & 1995 & 1996 & 1997 & 1998 \\
\hline NRK1 & 55 & 51 & 45 & 43 & 41 & 38 \\
NRK2 & - & - & - & 1 & 2 & 3 \\
TV2 & 19 & 24 & 30 & 32 & 31 & 30 \\
TVNorge & 8 & 8 & 8 & 7 & 8 & 9 \\
TV3 & 6 & 6 & 6 & 6 & 7 & 7 \\
Other & 11 & 11 & 12 & 11 & 11 & 13 \\
SUM & 99 & 100 & 101 & 100 & 100 & 100 \\
\hline
\end{tabular}

Source: Norwegian TV-meter panel MMI. 
Table 4. Market Shares in Prime Time (1900-2300). Total Television Population

\begin{tabular}{lrrrrrr} 
& 1993 & 1994 & 1995 & 1996 & 1997 & 1998 \\
\hline NRK1 & 59 & 56 & 52 & 49 & 47 & 45 \\
NRK2 & - & - & - & 2 & 3 & 3 \\
TV2 & 19 & 23 & 28 & 30 & 29 & 29 \\
TVNorge & 9 & 8 & 7 & 6 & 7 & 8 \\
TV3 & 5 & 5 & 5 & 5 & 6 & 6 \\
Other & 8 & 8 & 8 & 9 & 8 & 9 \\
SUM & 100 & 100 & 101 & 101 & 100 & 100 \\
\hline
\end{tabular}

Source: Norwegian TV-meter panel MMI.

NRK1 remains the dominant channel in terms of market shares. This is unusual, in most other European countries private channels have resumed the dominant position. The strong position of the NRK is even more remarkable when we take into account that NRK, during the period discussed here, transmitted for a much shorter period each day than its competitors (Part IV).

Indeed, if we look at the situation in prime time when all channels transmit a full schedule, NRK1 has an even stronger position: a market share of 45\% in 1998 against TV2's 29\% (Table 4).

Table 5. presents the market situation among the viewers who has access to all five Norwegian channels: the two NRK channels, TVNorge, TV2 and TV3. This reflects the situation in the densely populated parts of the country where competition for viewers and advertising revenue is the most intense. In this market, the major channels NRK and TV2 are far less dominant than in the population as a whole, whereas TV3, TVNorge and foreign channels have a stronger position. Nevertheless, this table also makes it clear why TVNorge's profitability has decreased in recent years (Part III). While TVNorge has increased its overall distribution, it has lost substantial market shares in the multichannel universe where the competition for advertising is the most intense. TV2, on the other hand, has strengthened its position as the dominant television advertising medium (see below).

Even though the major national channels remain dominant, there are, as already indicated, signs of fragmentation. In the years after TV2 first arrived, the combined market share of TV2 and NRK1 grew, but in later years the combined share of the two main channels are stagnating. In 1994, NRK1 and TV2 together commanded a $75 \%$ market share in the national universe, but this figure was reduced to $68 \%$ four years later. In the multi-channel population, the combined market share of TV2 and NRK1 was only $56 \%$ in 1998 . This indicates that for those who have a choice, almost half the viewing time was spent on foreign or specialised channels.

Table 5. Market Shares Television. Based on Multi-Channel Population (61\% in 1998)

\begin{tabular}{lcccccc} 
& 1993 & 1994 & 1995 & 1996 & 1997 & 1998 \\
\hline NRK1 & 40 & 41 & 35 & 34 & 34 & 32 \\
NRK2 & - & - & - & 1 & 3 & 3 \\
TV2 & 13 & 16 & 22 & 23 & 24 & 24 \\
TVNorge & 15 & 13 & 13 & 11 & 11 & 10 \\
TV3 & 13 & 11 & 11 & 12 & 11 & 11 \\
Other & 20 & 19 & 19 & 18 & 17 & 19 \\
SUM & 101 & 100 & 100 & 100 & 100 & 99
\end{tabular}

Source: Norwegian TV-meter panel MMI. 
Table 6. Television's Share of Total Advertising. Per cent

\begin{tabular}{lcccccc} 
& 1994 & 1995 & 1996 & 1997 & 1998 \\
\hline TV's share of total advertising & 17 & 19 & 20 & 23 & 24 & 24 \\
\hline
\end{tabular}

Source: Carat 1997, 1999.

\section{Advertising and Sponsorship: Markets and Distribution}

Television advertising has expanded enormously in the 1990s. There are several estimates for television advertising, which all give slightly different figures. The data in table 6 . is based on the actual income of the TV-companies and are therefore regarded as more accurate.

TV2 is the dominant television advertising medium. Its share of television advertising revenue grew to a peak of $70 \%$ in 1996 , then decreased to 64\% in 1998 (TV2 annual reports). Together with TVNorge, TV2 controls between $80 \%$ and $90 \%$ of the television advertising market. According to the Norwegian Competition Authorities (20.10.97), TVNorge's share was $14-15 \%$ in 1996 , the same as TV3's. Local television had a negligible share, less than $1 \%$.

The broadcasting sponsorship market is juvenile in Norway and no proper estimates exist for the total market. Still, it is clear that there has been a substantial increase in recent years. Sponsoring amounted to $2 \%$ of TVNorge's income, $4 \%$ of TV2's income, and 1\% of NRK's income in 1997. In $1997,30 \%$ of the sponsorship income to the NRK came from public sources (NRK and TV2 Annual reports, interviews).

\section{Competition for Events, Programming and Talent}

The increased competition for programme rights poses particular problems for national actors in small markets. In Scandinavia, bidders for the whole Nordic market, such as Kinnevik and Canal plus, are usually able to pay a higher price than operators covering only one country. NRK, TV2 and TVNorge have all have tried to overcome this situation by entering into alliances with other operators. NRK and TV2 have bought some rights together, but the general pattern is that these channels join forces with other national and Nordic channels.
NRK and TV2 are both EBU-members. The EBU is important for securing sports rights and exchanging news, but it is also organising and exchanging musical events. NRK is a member of Nordvisjon, the association of Nordic public broadcasters. Programmes are exchanged freely through this network, but this applies mostly to factual and children's' programmes - programmes with external right holders must be traded commercially. TV2 has developed an ad-hoc partnership with Swedish TV4 and Danish TV2. The three companies have exchanged some programmes and have also purchased some rights together. The alliance between TV2 and TVNorge (Part III) is important for the purchase of fiction and other entertainment programming.

As elsewhere, the prices on sports rights are the ones that are subject to the highest inflation; an increase of $50-100 \%$ in one year is not unusual. Competition is intense between the national operators and recent developments within pay and digital TV has led to further inflation. In 1995, NRK lost Premier League, which had been a permanent part of its schedule since 1969 , to TV2, but three years later, Canal+ was the one secure the rights. According to Aftenposten $(09.03 .98,10.3 .98)$, Canal+ doubled the price of 30 million NOK that TV2 had paid in for the Scandinavian rights in 1995. Through an agreement with Canal+, TV2 secured the rights to the Handball World Championship for men and women in 1999 and 2001. TV2 is the house broadcaster for the 1999 Championship.

NRK and TV2 control many important rights together. In April 1997, TV2 and NRK signed an agreement with the Norwegian Football Association for the period 1998-2001 worth 135 million NOK, and through EBU, TV2 and NRK have secured the rights to the 2000 and 2002 Olympic games. The negotiations between the channels as to which should transmit what has been rather volatile, however, and in 1999 NRK and TV2 transmitted parallel broadcasts from the Alpine skiing World Championship in Vail. This led to a public outcry that in turn pressured the two channels into 
a new round of negotiations. In the summer of 1999, an agreement emerged as to the distribution of events between the two operators.

The problems that apply to small operators in the sports rights market, is paralleled in the market for films and series. None of the large studios are interested in selling small quantities of programming, and in order to land down a contract, the buyer often has to guarantee that it will buy a certain amount of programming in the coming 3-5 years. These output deals grant the purchases the right to the first pick of the most attractive series, but in years with little attractive output, the channel must accept a certain volume anyway. A further complicating factor is that operators like Scandinavian Broadcast Systems (who owns part of TVNorge and have channels in many other European countries) and Kinnevik (major proprietor in TV3 and Viasat) usually bid for the Scandinavian rights as a whole. These bids also sometimes include the Baltic countries or Belgium and the Netherlands. In these cases, the Nordic channels need to find partners in the same countries in order to secure the rights.

The private channels, including TV2, have a large amount of foreign fiction in their schedules. Since 1993, TV2 has entered into several output deals with large US distributors: $20^{\text {th }}$ Century Fox and CBS, and through TVNorge, with Warner. Many of these deals are made jointly with TV4 in Sweden and Danish TV2. TV3 has a deal with Universal. NRK and its sister broadcasters in the other Nordic countries purchase far less package material than the commercial companies, and also, to a large extent, tries to avoid large output deals.

TV2 has put much money and effort into developing Norwegian soap operas and situation comedies, and is the only Norwegian channel to be a major purchaser of Norwegian fiction from external producers. Domestically produced fiction are in all cases much more expensive than fiction purchased from the US, even if costs are sometimes determined more by the product than the producing country. According to TV2's Finance Director a daytime soap opera produced in Norway cost approximately 100 times as much as a bought-in soap, whereas producing a Norwegian feature film cost 2-3 times more than purchasing a US film. In 1997, TV2 signed an agreement stating its intention to purchase 900 episodes of a new daily soap opera in Norwegian, Hotell Casar, for 320-350 million NOK (Aftenposten 22.02.98). This is one of the largest contracts ever signed between a European production company and a broadcaster. The production company Metronome Film and Television (wholly owned by one of TV2's main proprietors Schibsted) is paid approximately 3-400 000 NOK for one episode, which is less than half the price of TV2's first weekly soap opera Syv sфstre.

There is practically no demand for Norwegian produced fiction in other countries, and the possibilities for recapturing some of the investments through sales is very low. However, the co-operation between Nordic broadcasters sometime amount to them purchasing each other's programming. For example, TV4 has bought Syv sфstre from TV2 whereas TV2 has bought TV4's series Rederiet. Similar exchanges happen between the publicly owned broadcasters. In recent years, Nordic broadcasters have also been able to sell more programming to Baltic and Eastern European countries.

NRK's drama output is both more expensive and cheaper than that of the private companies. NRK is the only channel to produce and transmit and other single drama productions, and NRK is also alone in producing classic drama. According to the NRK Finance Director, income from funds and co-production agreements can help to cover some of the cost of Norwegian drama, but these funds cannot cover the total production costs. Regarding the film profile, NRK transmits significant amount of art films, historically significant films, short films and films from other than the dominant producing countries. Such films do not draw high ratings, but they have the advantage of being relatively inexpensive since there is no competition for them in the national market.

The competition for talent in the Norwegian market has so far been less distinct than the competition for rights. The private channels have been willing to pay more for high-profile entertainers and programme hosts, but many of them have had less success on commercial channels than they previously had on NRK. Nevertheless, many of the star performers and hosts are now operating on a freelance basis and payments are rising. The high number of permanent staff recruited in the 1970s, and the relatively low salary levels, has generally made it difficult for NRK to recruit new and attractive labour, and the rising prices on rights, programming and talent is generally a bigger problem for NRK than for other operators. A licence fee funded broadcaster cannot recapture the extra expenditure by attracting high ratings.

The increased competition for rights and talents is one of the main reasons why both licence-fee funded and advertising funded companies are get- 
ting involved in commercial activities. Conflicts with music right holders was one of the main reasons why TV2 purchased part of a record company (Part III), but once purchased, the company is also used to sign up talent for multimedia deals. Children's programmes are also being co-financed through spin-off agreements, both on NRK and TV2. NRK perceives it as a long-term risk that it may lose creative talent to media actors that can offer distribution through several outlets. This is yet one more reason why NRK wants to enter into partnership with other media businesses.

\section{Channels and Actors: Economic Characteristics and Financial Information}

The analysis of the Norwegian television market above demonstrated that the traditional Norwegian public broadcaster NRK still holds a dominant position in terms of market shares. As this chapter will show, the state owned broadcaster also has more money than its competitors to make programmes for. How substantial the difference between the channels is in this repsect, is nevertheless difficult to account for. There are no legal obligations as to how internal accounting should be carried out in the NRK, and during the period 1994 to 1997 , accounting followed the traditional pattern whereby overhead costs were not allocated to specific services. This system makes it difficult to identify the costs of different services, productions and genres, and makes it difficult to make comparisons between the NRK and other companies.

A second problem, which also makes it difficult to give a precise analysis of economic features, is confidentiality. In the cases were it is possible to identify the costs of various services, the broadcasters often prefer to keep the information confidential. Much of the information that was included in the original, confidential report, has consequently been omitted in this version. The twin problems of confidentiality and accountancy have consequently implied that the analysis in this chapter is more superficial than we would prefer it to be.

This chapter includes economic and financial information on NRK, TV2, TVNorge, Canal Digital and Viasat.

\section{$N R K$}

NRK is a multi-media broadcaster that operates three national radio channels and two digital target channels, two television channels, an internet ser- vice, 17 regional offices and a unit which produces programming for the sámi population. NRK has undergone major reorganisations in the last 10-15 years in an attempt to become less of a state department and more of a modern media company. In the 1990 s, it has rationalised its production structure and introduced more competitive scheduling practices. Two new divisions are recently established: NRK Resources will "sell" its services to other NRK divisions and external buyers. A new division, NYDI, integrates all news and regional service into one large bi-media directorate.

As mentioned above, NRK's accounting in the period discussed here followed the traditional pattern whereby overhead costs were not allocated to specific services. A more transparent cost/management model was introduced from 1999, but has no bearing on the present study. NRK's accounting differs also in other respect from that of the other channels. In NRK, the practice is to return each department's share of additional income (sponsorship etc.) to the department that attracted the revenue.

\section{Economic Features}

NRK is a limited company where the state holds all the shares. The share capital of NRK is NOK 1.000.000.000. The NRK group's balance for 1998 shows the equity's share of the total capital to be $58 \%$ (59\% in 1997). NRK's debts, the remaining $42 \%$ of the total capital (41\% in 1997) are dominated by items such as public fees and pension payments; debts which any large company is bound to have (Table 7).

NRK does not have any long-term loans and pays little interest. Financial costs are therefore very low. If the NRK were a private company, with the same income, its financial situation would be very good. However, as a state-owned company, NRK's ability to operate in financial markets is restricted. The NRK Regulations specify that "the NRK debt and guarantee responsibility shall not depass $50 \%$ of the yearly licence fee proceeds, and shall, independent of than fact, be upwards limited to the total of share capital and funds". Both in 1996 and 1997 the NRK had to use money from its revenue reserve to cover deficits. Table 8 . presents the financial situation for the whole NRK group (including radio, the regional division, distribution and overhead).

The licence fee is the main income for the NRK. This is a combined licence for radio and TV tat anyone with a television set is liable to pay. The board has proposed that the licence fee should be linked with the Retail Price Index (NRK newsletter 
Table 7. NRK Balance Sheet. Millions NOK

\begin{tabular}{lrrrrrr} 
& 1993 & 1994 & 1995 & 1996 & 1997 & 1998 \\
\hline Total current assets & 1002 & 910 & 881 & 928 & 955 & 950 \\
Total capital assets & 1548 & 1544 & 1621 & 1662 & 1562 & 1557 \\
Total assets & 2550 & 2454 & 2501 & 2590 & 2517 & 2506 \\
Total debts & 822 & 713 & 899 & 973 & 1046 & 1055 \\
Total equity & 1644 & 1671 & 1600 & 1617 & 1471 & 1451 \\
Total capital $^{1}$ & 2550 & 2454 & 2500 & 2590 & 2517 & 2506 \\
\hline
\end{tabular}

${ }^{1}$ The sums for 1993, 1994 and 1995 do not add up. The reasons are that the company allocated money to funds and reserves (84 millions in 1993, 69 millions in 1994 and 1 million in 1995).

Source: NRK Annual reports.

Table 8. NRK Profit and Loss Accounts. Millions NOK

\begin{tabular}{|c|c|c|c|c|c|c|}
\hline & 1993 & 1994 & 1995 & 1996 & 1997 & 1998 \\
\hline Licence fee income & 1884 & 2007 & 2190 & 2343 & 2457 & 2607 \\
\hline Other income & 521 & 497 & 182 & 176 & 173 & 256 \\
\hline Total income & 2405 & 2503 & 2372 & 2519 & 2630 & 2863 \\
\hline Operating costs & 2210 & 2307 & 2200 & 2748 & 2823 & 2925 \\
\hline Deprecations ${ }^{1}$ & 225 & 226 & 232 & & & \\
\hline Operating result & -31 & -29 & -61 & -229 & -193 & -62 \\
\hline Net financial items & 66 & 41 & 38 & 39 & 51 & 42 \\
\hline $\begin{array}{l}\text { Result before } \\
\text { extraordinary posts }\end{array}$ & & & & -190 & -142 & -20 \\
\hline Extraordinary posts ${ }^{2}$ & & & & 264 & & \\
\hline Total appropriations & 33 & 16 & 14 & & & \\
\hline Profit after tax & 1 & 27 & -8 & 74 & -142 & -20 \\
\hline
\end{tabular}

${ }^{1}$ The accounting system for the year 1996 onwards is different from other years. Among other things, deprecations are part of the operating costs.

${ }^{2}$ The 1996 figure is income from sale of the transmission network (sold to Norkring which is a separate company owned jointly by NRK and Telenor).

Source: NRK Annual Reports.

01.29.98). This has not been accomplished, and the level of the fee is still determined annually by Parliament. According to NRK, Norway had had one of the highest proportions of licence evaders in $\mathrm{Eu}$ rope in the early 1990s. Sustained efforts have brought the figure down to $10 \%$ in 1998 .

Other income comes from programme funds, coproductions and sponsorship. 1993 and 1994 are exceptional years due to income from the tax on receiving equipment (later abolished) and income related to the Olympics in Lillehammer in 1994. Both in 1997 and 1998, sponsorship revenue amounted to 26 million NOK for the whole corporation, a figure which equals the "sponsorship quota" allocated to NRK (Part I).
The NRK as a whole had a operating deficit of 190 million NOK in 1996 and 142 million NOK in 1997. The deficit was, in particular, due to expansions in the regions, establishment of NRK2 and new radio channels, and rising programme costs. While extra licence fee funding has been allocated for regional television developments, no additional revenue was granted to the corporation for the establishment of NRK2. The 1997 deficit is covered in part by the profit on the sale of the transmission network, which took place in 1996, in addition to money from capital reserve funds. In 1998 the deficit was reduced to 20 mill NOK.

In the years to come, NRK is hoping to generate additional revenue through the commercial subsidi- 
ary NRK Aktivum, which was established in 1997. Aktivum has budgeted with a small surplus in 1999 and a more substantial surplus from the year 2000. The company will, among other things, buy programme rights that it will either resell to NRKtelevision, present on its pay-TV channel NRK International or sell on video. NRK International is aimed at Norwegians abroad and currently (1999) has less than 700 subscribers. The company also wish to enter into joint ventures with commercial companies in a variety of areas, but this is dependent on NRK being granted the changes it has asked for in the Broadcasting Act (Part I).

\section{Cost and Revenue: NRK Television Division}

In the previous section the financial analysis of the whole corporation was discussed. This section presents information specifically about the television division, the division responsible for television programming only. Income from the licence fee is allocated to the various NRK divisions after internal budget negotiations: television and radio divisions, regional division, distribution, central staff, the Director-General's staff, research and marketing, financial staff, buildings etc. Table 9. shows the proportion of licence fee and other income allocated specifically to the TV division. As the table demonstrates, the amount of revenue allocated to television increased substantially in 1996, when NRK2 was established. Generally, between 30 and $35 \%$ of the annual licence fee revenue has been allocated to the television division in the period 1993-97.

Table 10. presents the main costs for the NRK television division between 1993-1997. The cost of salaries, travel and general programme costs are born by the various departments of the division (news, drama, factual programming etc.), whereas the costs of technology, studios, design etc. is placed in the television division as general over-

Table 9. NRK TV-division's Share of the Licence Fee. Millions NOK

\begin{tabular}{lrrrrr} 
& 1993 & 1994 & 1995 & 1996 & 1997 \\
\hline Licence fee income & 642 & 641 & 639 & 822 & 820 \\
Other income & na & na & 75 & 99 & 84 \\
\hline
\end{tabular}

Source: Director of Finance, NRK. na - not available.

Table 10. NRK Television. Total Costs 1993-97. Millions NOK

\begin{tabular}{lrrrrr} 
& 1993 & 1994 & 1995 & 1996 & 1997 \\
\hline Personnel costs & 485 & 490 & 497 & 622 & 622 \\
$\begin{array}{l}\text { Programme acquisitions } \\
\text { Travel expenses }\end{array}$ & 30 & 33 & 33 & 55 & 64 \\
$\begin{array}{l}\text { Material, technical and } \\
\text { other acquisitions }\end{array}$ & 37 & 45 & 37 & 43 & 42 \\
$\begin{array}{l}\text { Payment to right holders } \\
\text { (sport, news, music etc.) }\end{array}$ & 33 & 32 & 36 & 56 & 37 \\
Net internal trading & 10 & 15 & 16 & 19 & 22 \\
$\begin{array}{l}\text { House rent, maintenance of } \\
\text { buildings, office equipment, }\end{array}$ & 11 & -2 & 12 & 5 & $22^{1}$ \\
marketing and PR etc. & 18 & 14 & 15 & 19 & \\
Other costs & 60 & 95 & 63 & 112 & 90 \\
Financial costs & 0,2 & 0,3 & 0,1 & 0,2 & 0,5 \\
SUM costs & 686 & 723 & 709 & 932 & 917 \\
\hline
\end{tabular}

${ }^{1}$ NRK-TV has bought services from other divisions at the cost of 96 mill. NOK in 1997. The income from sale to other divisions was 73 mill. NOK, hence the net cost of 22 mill. NOK under this item.

Source: Director of Finance, NRK. 
head. Transmission costs, costs of central staffs, regional productions, maintenance of building etc. are part of the budget of the whole corporation and not included in table 10 .

Table 10. demonstrates that personnel costs are, by far, the largest costs for NRK television. The costs continues to increase nominally on an annual basis, whereas the proportionally these costs are stable (between 67 and $70 \%$ of the annual costs). Over the last decade there has been several major labour conflicts in the NRK, but the salary level is still lagging considerably behind the private media. In contrast to other broadcasters in Europe, NRK has not had any forced redundancies, but has attempted several voluntary redundancy programmes. NRK television had 1130 employees in 1997, a number that is high compared to other broadcasters in Norway, but low compared to other Nordic and European public television stations (Nordicom 1999). I 1999 the number of employees in the television division had shrunk to 520, while 1329 had been transferred to the newly established bi-media news and regional division (NYDI).

The costs that have risen the most in relative terms between 1993 and 1997 are the costs of rights and programme acquisitions (from $4 \%$ in 1993 to 7\% in 1997). In addition, sports and film rights, payments to music rights holders and news wire services have increased substantially (from $1.4 \%$ of the costs in 1993 to $1.9 \%$ in 1997).

\section{TV2}

TV2 is a shareholding company owned by Norwegian and Nordic media interests. There is a maximum limit per shareholder of $33.33 \%$ of the shares, but the Government has proposed that this nominal limit should be lifted and the responsibility transferred to the media Ownership Authority (Part I). The shareholders pr. 1.1.1999 were Schibsted $33,33 \%$; Egmont Holding 33,22\%, A-pressen 22,20 $\%$, A-pressen TV $11 \%$, others $0,25 \%$. TV2s proprietors control large parts of the Norwegian media market: production companies, newspapers, magazines etc. Schibsted is, by far, the largest media company in Norway, it owns the two biggest newspapers and a host of other Scandinavian media enterprises. A-pressen is the consortium of (previous) Labour Party newspapers that also controls many local TV stations. Egmont is a large Danish media enterprise that also has substantial holdings in the Norwegian print media market.
TV2's strategy from the beginning has been to become the dominant outlet for television advertising and most of the efforts have gone into competing with TVNorge and TV3. TV2 is not expecting to expand further in the advertising and audience markets, but rather to consolidate its position and move into other fields. As other broadcasters, it has been positioning itself as a content provider and has been exploring the possibilities for commercialising various parts of its operations. This is a controversial policy and there are signs (late 1999) that it may be reversed. By the end of 1998, however, TV2 owned shares in 21 companies. Several of these it owned together with one or more of its proprietors (Table 11).

Protecting its market has been a further part of TV2's strategy. In 1997, TV2 bought a 49\% share in TVNorge and in September the same year, an agreement was signed which granted TV2 control over programming on TVNorge for the next four and a half years. This agreement turned out to be costly for TV2 and was terminated in 1999 (see below). In July 1998 TV2 bought a 16\% share in Canal Digital Norway. TV2 has also reached an agreement with Canal Digital to have TV2 and TVNorge included in its digital television package (see below).

\section{Economic Features}

After a difficult beginning in 1992-93, TV2 made substantial profits from 1994. In 1997, TV2's turnover for the first time passed 1 billion NOK and the total operating revenue for the parent company (the original television company) showed a $19 \%$ increase over 1996. It is the core activities that have been responsible for the profits. The subsidiaries, including TVNorge, have so far amounted to extra expenditure for the company (see page 89).

It is difficult to estimate what TV2's distribution privilege is worth, but it is clear that it has been a precondition for a substantial proportion of the profits. In contrast to what is the case in most other countries, TV2 does not pay a fee for the privilege of distributing terrestrial commercial television. In 1995, TV2 filed a lawsuit against the state asking for a compensation of 900 million NOK after Parliament had allowed TVNorge to link up with a network of local television stations (St. meld. 24 1994-95). TV2 argued that this decision undermined the value of its distribution privilege. The lawsuit was later dropped, but this is an indication of what the terrestrial privilege is worth 
Table 11. TV2's Subsidiaries 1998

Name of company

TV2s share

Tempelkroken Invest as

$100 \%$

Storm Weather Center as (commercial weather service) 9 90,5\%

Nyhetssentralen Byrå 2 as (news agency) $100 \%$

Pilot broadcasting Systems as $91 \%$

Peak Software Technologies GmbH $\quad 40 \%$

$\begin{array}{ll}\text { Brann Stadion as (football team) } & 7,5 \%\end{array}$

$\begin{array}{ll}\text { Nydalen Studios as } & 100 \%\end{array}$

Outside broadcast Team as $\quad 100 \%$

Eventyrkanalen (technical operating company for TVNorge) $\quad 100 \%$

Norske Gram as (record company) $\quad 100 \%$

Trondheim Rock Cafe as $\quad 34 \%$

Norske Gram Event as $\quad 100 \%$

Shop in shop as $100 \%$

TV2 Gruppen as $100 \%$

TV Torget as (home shopping) $51 \%$

Net 2 Interaktiv as (sells advertising for TV2's teletext service) $\quad 100 \%$

$\begin{array}{ll}\text { TVNorge as } & 49,3 \%\end{array}$

Nordic Shopping Channel Ltd $\quad 48,6 \%$

Hit Company management as $\quad 21 \%$

Rettighetsselskapet Intrige as $\quad 33,33 \%$

Canal Digital Norge as $16 \%$

Source: TV2 Annual Report.

Table 12. TV2 Consolidated. Balance Sheet 1993-98. Millions NOK

\begin{tabular}{|c|c|c|c|c|c|c|}
\hline & 1993 & 1994 & 1995 & 1996 & 1997 & 1998 \\
\hline Total current assets & 202 & 454 & 630 & 746 & 604 & 630 \\
\hline Total capital assets & 99 & 94 & 118 & 116 & 433 & 436 \\
\hline Total assets & 301 & 548 & 747 & 861 & 1037 & 1066 \\
\hline Total debts & 292 & 453 & 462 & 511 & 616 & 611 \\
\hline Total equity & 9 & 95 & 285 & 293 & 418 & 453 \\
\hline Total capital & 301 & 548 & 747 & 861 & 1037 & 1066 \\
\hline
\end{tabular}

Source: TV2 Annual reports.

to TV2. A final indication that the privilege is important is that TV2 has been able to raise its advertising prices with $15-20 \%$ annually over the last years, without any fallout in advertising revenue.

Naturally, TV2's balance shows a lower proportion of equity to total capital than NRK's (Table 12). The percentage was $42 \%$ in 1998 , an improve- ment from $40 \%$ in 1997 and $34 \%$ in 1996 . The improvement is due to the considerable profits, much of which has been held back to strengthen the equity. In 1997, TV2 obtained a loan of 100 mill. NOK that appears to have been used to cover investments in other companies (amont them TVNorge - see below). The item "Investments in 
Table 13. TV2 group (with subsidiaries). Profit and Loss Account. Millions NOK

\begin{tabular}{lrrrrrr} 
& 1993 & 1994 & 1995 & 1996 & 1997 & 1998 \\
\hline Income & 340 & 554 & 784 & 898 & 1070 & 1336 \\
Operating costs & 480 & 511 & 670 & 775 & 914 & 1128 \\
Operating result & -139 & 43 & 114 & 124 & 156 & 154 \\
Financial revenue/costs & 3 & -7 & -1 & 10 & 7 & -13 \\
Surplus before tax & -136 & 36 & 113 & 133 & 163 & 161 \\
Profit after tax & -136 & 36 & 107 & 94 & 99 & 84 \\
\hline
\end{tabular}

Source: TV2 Annual reports.

Table 14. TV2. Total Operating Costs. Parent Company (excl. subsidiaries). Millions NOK

\begin{tabular}{lrrrrrr} 
& 1993 & 1994 & 1995 & 1996 & 1997 & 1998 \\
\hline Programme costs & 165 & 178 & 241 & 279 & 293 & 331 \\
Personnel costs & 115 & 120 & 143 & 163 & 201 & 239 \\
House rent. & 18 & 16 & 18 & 22 & 23 & 28 \\
Marketing, PR & 10 & 14 & 17 & 20 & 15 & 14 \\
Travel costs & 20 & 21 & 26 & 24 & 31 & 38 \\
Administrative costs & 16 & 15 & 25 & 29 & 31 & 52 \\
TV+ & - & 31 & - & - & 0 & 0 \\
Distribution/ & & & & & & \\
communication & 100 & 108 & 122 & 133 & 137 & 123 \\
Other operating costs & 15 & 15 & 18 & 41 & 45 & 98 \\
Ordinary deprecations & 22 & 25 & 30 & 37 & 39 & 41 \\
Bad debts & - & 1 & 1 & 3 & 4 & 0 \\
SUM costs & 480 & 511 & 670 & 751 & 820 & 964 \\
\hline
\end{tabular}

Source: TV2 Annual Reports.

Table 15. TV2 Specification of Programme Costs. Millions NOK

\begin{tabular}{lcccccc} 
& 1993 & 1994 & 1995 & 1996 & 1997 & 1998 \\
\hline Films, own productions & 68 & 88 & 147 & 139 & 173 & 144 \\
Programme acquisitions & 65 & 60 & 56 & 72 & 60 & 85 \\
Rights & 144 & 13 & 13 & 41 & 39 & 82 \\
Fees & 19 & 18 & 23 & 27 & 21 & 20 \\
SUM costs & 165 & 178 & 241 & 279 & 293 & 331 \\
\hline
\end{tabular}

Source: TV2 Annual reports. 
related activities" increased from near zero in 1996 to 234 mill. NOK in 1997. In 1998, 175 mill. NOK was spent on investments in related activities.

Table 13 presents the profit and loss account of the whole TV2 group (including subsidiaries). The table demonstrates that the company is solid in financial terms and, at least until 1998, generated more than enough revenue to cover its costs. In the summer of 1997, the price of the TV2 shares indicated that the company was worth around 2 billion NOK. In contrast, TVNorge estimated value was only around half a billion NOK (Aftenposten 26.6.97).

Recent developments (spring 1999) have been less positive for TV2. During the first six months of 1999, the TV2 group had a deficit of 8.5 mill. NOK. The income was lower and the costs higher than in the first six months of 1998. In addition, the agreement with TVNorge turned out to be very costly for TV2.

\section{The Relationship Between TV2 and TVNorge}

In 1997, TV2 bought a 49\% share of TVNorge for 284 million NOK. In September the same year, an agreement was signed which granted TV2 control over programming on TVNorge for the next four and a half years. Programme production, programming and strategy was the responsibility of TV2, while the two channels still kept separate sales departments. The plan was that TVNorge should continue to increase its distribution network, generate more gross rating points and increase its market shares, preferably without damaging TV2's position. As part of the agreement, TV2 guaranteed TVNorge a certain GRP production on an annual and accumulated level, and committed itself to pay compensation if this was not achieved.

As it turned out, TVNorge only increased its market share marginally in 1998, and its market share in the multi-channel universe decreased. At the same time, TV2s market shares stagnated in both markets (Part II). In this situation, TV2 was obliged both to cover parts of TVNorges deficit and to pay compensation to TVNorge. TV2 paid 25 mill. NOK to TVNorge in 1998 and a further 45 mill NOK during the first six months of 1999. In October 1999, the two parties agreed that TV2 should pay TVNorge a final compensation of 365 mill. NOK in order to have the agreement terminated. When tax benefits and TV2's "income" from the agreement is deducted (TV2 still owns $49 \%$ of TVNorge), the sum is 76 mill. NOK annually for two years (Aftenposten 27.10). Formally, TV2s responsibility for programming on TVNorge ends 1.1.2000.

\section{Cost and Revenue: TV2 Television}

So far, we have discussed the situation for the whole TV2 group. In this section we present financial information about the parent company, TV2 television. This remains the core enterprise and is also the enterprise responsible for bringing in the revenue.

Around $98 \%$ of the operating income of TV2 (parent company only) come from advertising and sponsorship. Sponsorship equals about $4 \%$ and the amount has increased considerably since 1993. In 1998 TV2s income from advertising was 1122 mill. NOK and from sponsorship 45 mill. NOK. Other income amounted to 67 mill. NOK and include programme sales, video sales and sale of smart cards for satellite reception (estimates based on information from TV2's Finance Director and TV2 Annual reports).

Income is not distributed among the different departments in TV2. They only have cost budgets. However, the departments have more or less formalised costs norms for how much they can spend on different kinds of programming. Sale of spin-off products is allocated back to the holding company, and is not allocated to the unit that is responsible for production.

The main costs for TV2 is programme acquisitions as only news, current affairs and sports are produced in-house (Table 14.). There has been a substantial nominal increase in programme costs over the last years, but these costs still amount to the same proportion in 1993 and 1998 (34\%). Personnel costs are also a large cost item for the TV2 (25\% of the costs in 1998). In 1998 the company employed 415 people and salaries are generally higher than in NRK. In table 14. the salaries for TV2s journalists who produce news and current affairs are included in the personnel costs and not in the programme costs.

In table 15. the programme costs are specified in more detail:

TV2's Finance Director estimated in 1997 that $16 \%$ of its total cost were linked with news and current affairs, $10 \%$ with sports, $22 \%$ with Norwegian productions and $10 \%$ with purchased films and series. The remaining were technical (24\%) and other costs $(18 \%)$. 


\section{TVNorge}

TVNorge began broadcasting in 1988 as the first Norwegian advertisement-funded television channel, distributed through cable and satellite. TV Norge was established by four Norwegian businessmen, but in 1993, the media investment company Scandinavian Broadcast Systems (SBS) bought an $89 \%$ share in the company. In 1996, TVNorge's production unit was sold out and major changes were made in order to equip TVNorge to compete better with TV2. The strategy was unsuccessful, and in 1997 TV2 and its proprietors began buying into the company. In 1998 TV2 held 49,3\% of the shares in TVNorge, while SBS held 50,7\% (the relationship between TV2 and TVNorge is discussed above).

TVNorge has no subsidiaries but operates a teletext service: TvNorge Interaktiv AS. In 1996, Parliament made it legal for TVNorge to co-operate with a network of local channels, a fact that has helped TVNorge increase its distribution substantially.

\section{Economic Features}

TVNorge made a profit until 1994, when the competition from TV2 could be felt more directly. The 1996 accounts show that the deficit amounted to 142 million NOK and TVNorge's capital balance for 1996 show a negative equity of 65 million NOK. The 1997 balance shows a deficit of 133 mill. NOK (Table 16.). It seems that the company might have been heading towards bankruptcy had major changes not been made.

\section{Cost and Revenue: TVNorge}

Advertising is the main income of TVNorge. In 1998, TVNorge generated 276 mill. NOK in advertising revenue, up from 197 mill. NOK in 1997.
Sponsorship constitutes $2 \%$ of advertising revenue and the proportion has been stable in the period 1993-97. In 1997 TVNorge attracted 45 mill. NOK in other revenue (the renting out of technical capacity and some other income), but this was an unusual year. In 1998 other income only amounted to 6 mill. NOK. TVNorge has no income from spin off sales etc. (TVNorge Accounts, TVNorge Finance Director).

As table 17. demonstrates TVNorge's costs have increased considerably in the latter years. This is mainly due to investments related to transmission and co-operation with local television.

Programme costs are divided between "purchases of films and series" and "local productions". The news operation is included in local productions. Programme costs represented approximately $46 \%$ of total operating costs for 1998 while distribution costs amounted to $28 \%$. Distribution costs include local-TV distribution, satellite expenditure and communication (linjeleie). In 1993, TVNorge had a major in-house production facility, but this part was sold out in 1996.

\section{TV3}

TV3 is almost wholly owned by the Swedish industrial corporation Kinnevik and is part of a panScandinavian multi-channel operation. In 1990, TV3 split the signals and began a specific Norwegian service, but TV3 has continued to transmit from London. TV3 has around 50 employees in Norway, working mostly within administration, finance, sales, planning and research. TV3's headquarter in London is responsible for purchasing rights and programmes for all national services. TV3 also commissions joint productions for the various national services. No financial information regarding TV3 is included here.

Table 16. TVNorge Balance Sheets. Millons NOK

\begin{tabular}{lrrrrrr} 
& 1993 & 1994 & 1995 & 1996 & 1997 & 1998 \\
\hline Income & 156 & 205 & 218 & 181 & 243 & 281 \\
Operating costs & 135 & 181 & 223 & 320 & 364 & 377 \\
Operating results & 21 & 25 & -5 & -139 & -120 & -96 \\
Financial revenue/costs & 0,2 & 4 & 5 & -3 & -13 & -12 \\
Surplus before tax & 21 & 29 & -1 & -142 & -133 & -108 \\
Profit after tax & 21 & 29 & -1 & -142 & -133 & -108 \\
\hline
\end{tabular}

Source: TVNorge Balance sheets (Brønnøysundregistrene). 
Table 17. TVNorge Total Operating Costs. Millions NOK

\begin{tabular}{|c|c|c|c|c|c|c|}
\hline & $1993^{1}$ & 1994 & 1995 & 1996 & 1997 & 1998 \\
\hline Programme costs & 69 & 95 & 115 & 160 & 147 & 174 \\
\hline Personnel costs & 41 & 54 & 66 & 65 & 41 & 41 \\
\hline Distribution costs ${ }^{2}$ & - & - & - & - & 126 & 104 \\
\hline Sales and administration & 24 & 33 & 33 & 83 & 39 & 49 \\
\hline Write-offs & 5 & 7 & 9 & 10 & 11 & 9 \\
\hline Losses on claims & 0,2 & 0,2 & 0,1 & 1,1 & 0,1 & 0,7 \\
\hline SUM costs & 135 & 181 & 223 & 320 & 364 & 377 \\
\hline
\end{tabular}

${ }^{1}$ I 1993 the cost accounts are organised differently than in later years.

${ }^{2}$ Distribution costs are not specified 1993-96.

Source: TVNorge accounts (Brønnøysundregistrene).

\section{Viasat and Canal Digital}

In addition to the general services there are two main pay-TV operators in Norway, Viasat and Canal Digital. So far, these channels have little economic significance, but it is worth including some information on them as they are expanding rapidly within the Norwegian context. Both Viasat and Canal Digital are subscription management operators, only offering packages of already existing channels, therefore the two companies have no licence agreement and no editorial responsibility for the content that is transmitted. According to managers of the pay-TV services, Pay-TV commands around 5\% of the total television viewing time in 1998, and each operator has a market share of around 50\%.

Viasat is a subscription management operator for TV1000 and TV3. Viasat is owned by Modern Times Group, which is linked with companies within the Kinnevik group In 1998 Viasat had around 250000 subscribers in Norway, including subscribers who only had TV3 (TV3 has been encrypted from the beginning). Table 18. present balance sheets for Viasat.

Table 18. Viasat Balance Sheet. Millions NOK
Canal Digital Norway is a subsidiary of Canal Digital Norden (Nordic) which is owned $50 / 50$ by Telenor, the Norwegian Telecom, and Canal+. Canal Digital Norden is headquartered in Oslo and is responsible for technological matters and the purchase of transmission rights. It has subsidiaries in all Nordic countries (except Iceland); these companies are responsible for customer service, sales and marketing in each market. TV2 recently gained a share in the Norwegian subsidiary (16\%). Canal Digital Norway has 50 employees. From the autumn of 1998 it offered a digital package to satellite dish owners including an electronic programme guide (EPG), and various Internet services. Included in the package are national channels like NRK1\&2, TV2 and TVNorge, film and sports channels, and target channels like CNN, National Geographic etc.

In financial terms, Canal Digital Norway is a continuation of the film channel Filmnet, which began its activities in Norway in 1986. Later the company changed name to MultiChoice, a company wholly owned by NetHold Western Europe BH. In January 1997 Telenor and Nethold entered into a

\begin{tabular}{lrrrrrr} 
& 1993 & 1994 & 1995 & 1996 & 1997 & 1998 \\
\hline Income & 21 & 28 & 39 & 46 & 61 & 99 \\
Operating costs & 15 & 19 & 27 & 33 & 58 & 96 \\
Operating results & 6 & 9 & 12 & 13 & 3 & 3 \\
Profit after tax & 3 & 7 & 11 & 12 & 3 & 4 \\
\hline
\end{tabular}

Source: Viasat accounts (Brønnøysundregistrene). 
Table 19. Canal Digital Balance Sheet. Millions NOK

\begin{tabular}{lcccccc} 
& 1993 & 1994 & 1995 & 1996 & 1997 & 1998 \\
\hline Operating revenue & 104 & 113 & 78 & 127 & 101 & 177 \\
Operating costs & 113 & 152 & 99 & 171 & 166 & 228 \\
Operating profit & -8 & -38 & -21 & -44 & -56 & -51 \\
Profit after tax & -8 & -39 & -21 & -46 & -53 & -56 \\
\hline
\end{tabular}

Source: Canal Digital accounts (Brønnøysundregistrene).

partnership to establish digital television, but NetHold was soon after bought by Canalt.

Canal+ is distributed by Canal Digital and several cable operators. Canal Digital is positioning itself to be the major actor within digital television. What is noteworthy, however, is that neither the "old" FilmNet or Canal Digital has so far made a profit (in contrast to Viasat that has made a profit for several years). Managing Director Espen Asheim of Canal Digital says that the company is budgeting with a surplus from 2001. According to newspaper articles, the current owners invested 300 million NOK in the company in 1997 (Aftenposten 3.6.98). Table 19 presents the balance sheet for Canal Digital.

Sale of the smart cards necessary to activate decoders is the main income of Canal Digital and Viasat. The cards are sold through radio and TV retailers. Cards are also rented out, but income from this is marginal. The largest costs are programme and distribution costs.

\section{Programme Analysis}

The above discussion has demonstrated that the costs of broadcasting vary substantially between different operators. These variations correspond with differences in programming. Whatever indicator is applied, the most distinct difference can be found between NRK on the one hand and all the advertisement-funded channels on the other. Regarding some forms of programming, there are also important differences between TV2 and other private channels.

\section{Output, Scheduling, Repeats}

None of the main services broadcasting in Norwegian are providing a 24 hour service. Most of the output is still concentrated in the evenings, although there are major variations. NRK's main strategy in the 1990s has been to expand early evening and prime time programming; but from the autumn of 1999 it has also introduced a breakfast service and more programming in the early afternoon. NRK2 is only broadcasting during prime time; in the daytime its transmission network is used by other services (home shopping, religious services). TV2 has been expanding its schedule continuously and began transmitting at breakfast time in 1994. TV3 has the most extensive service of all channels broadcasting in Norwegian. With 140 hours a week in 1997 (of a possible 168) it is not far from a continuos service. TVNorge has traditionally been more like NRK1, but has lately expanded its schedule (Table 20).

TV2 and the other private channels have highly structured schedules with extensive use of "stripping" - the placing of identical programmes and series in horizontal strips throughout the week. They all practice the principle of "block programming" in prime time; a series of mass appeal programmes placed "back-to-back" through the night. The NRK schedule has traditionally been more loosely structured, but with the impact of competition, more competitive scheduling policies have been introduced. Particularly during the weekends, new scheduling principles have been instrumental in holding on to the viewers. The second channel, NRK2, is more tightly scheduled than NRK1. Still, the NRK broadcasts more varied programming within prime time than any of the other channels and have a much more substantial amount of single programmes and shorter series/serials. Particularly in the latter part of prime time and on NRK2, the schedule is very varied. NRK is the only channel to schedule extensive amounts of children \& youth programmes, educational and cultural programming, and in-depth documentaries during early evening and prime time.

The proportion of repeats also varies significantly between the channels. As table 21 demon- 
Table 20. Output: Total Number of Hours per Week. All Channels

\begin{tabular}{lrrrrrr} 
& 1993 & 1994 & 1995 & 1996 & 1997 & 1998 \\
\hline NRK1 & 65 & 68 & 69 & 78 & 75 & 78 \\
NRK2 & - & - & - & 48 & 36 & 42 \\
TV2 & 65 & 71 & 92 & 100 & 105 & 115 \\
TVNorge & 66 & 70 & 73 & 75 & 89 & 94 \\
TV3-Norway & 80 & 115 & 129 & 140 & 140 & 140 \\
\hline
\end{tabular}

Source: Nordic Media Trends 1997, 1998, NRK Annual reports, TV2 Annual reports, TVNorge research, TV3 research.

Table 21. Share of Repeats. NRK and TV2. Per cent

\begin{tabular}{lrrrrrr} 
& 1993 & 1994 & 1995 & 1996 & 1997 & 1998 \\
\hline NRK1 & 16 & 18 & 18 & 20 & 20 & 22 \\
NRK2 & - & - & - & 10 & 21 & 32 \\
TV2 & na & 10 & 11 & 20 & 31 & 37 \\
\hline
\end{tabular}

Source: NRK annual reports, NRK programundersøkelser, TV2 annual reports. na - not available.

strates, NRK has increased its share of repeats, as was intended, after the second channel began broadcasting in 1996. TV2 has more than doubled its share of repeats in recent years, and in 1998 more than one third of the programmes were repeats. The reason given by TV2 is that transmission rights for much purchased material was about to expire and had to be used in order not to loose money (TV2 annual report 1997, 1998). The proportion of repeats has an important impact on the cost of programming as these are much less expensive than first-run programmes.

TVNorge and TV 3 provides no data on the proportion of repeats, but an informal survey of the schedules indicate that the proportion must be closer to TV2's than NRK's. A limited investigation into one week of summer programming (week 30 1998), conducted by the Norwegian newspaper Dagbladet (28.7.98), concluded that the share of repeats on various channels were: NRK1 21\%; NRK2 41\%, TV2 54\% and TVNorge 51\%. For all channels apart from NRK1, the proportion of repeats is apparently higher in the summer than in the rest of the year.

Although the share of repeats is important, it is nevertheless very difficult to estimate it correctly. The above table only indicates repeats of whole programmes; it does not say anything about repeats within programmes. In Breakfast-TV, for example, many segments are repeated several times. The same goes for news, sports, weather and magazine programmes; they might have a higher or lower degree of repeats within each programme and throughout the day. There is also a very high degree of repeats in promotion material and advertising which is not specifically calculated.

\section{Origin of Programmes}

The channels also vary much in terms of where they get their programming from. Table 22. and 23. contain information about the origin of programming on NRK and TV2. Table 24. also include some information about TVNorge.

The main difference between the two channels' Norwegian programming is that while TV2 commissions a large proportion of its output, only between $4 \%$ and $5 \%$ of NRK output is commissioned from independent producers. NRK diverse production apparatus is clearly visible in table $22: 1 \%$ of the television output in 1997 was produced by foreign correspondents and 7\% was produced in the regions. Overall, the NRK has a slightly higher share of Norwegian programming than TV2, but the difference in Non-Nordic programming is more marked $(47 \%$ on TV2 against $41 \%$ on NRK in 1997). Nordic programming is generally more expensive than programming from larger countries. 
Table 22. NRK 1 and 2: Origin of Programmes. Per Cent of First Run Programmes (repeats excluded)

\begin{tabular}{lrrrr} 
& 1994 & 1995 & 1996 & 1997 \\
\hline Central productions & 43 & 40 & 34 & 34 \\
Regional productions & 8 & 8 & 7 & 7 \\
Foreign correspondents & 1 & 1 & 1 & 1 \\
Unspecified own productions & 3 & 7 & 10 & 9 \\
Norwegian external producers & 4 & 4 & 5 & 4 \\
Nordic productions & 6 & 5 & 5 & 4 \\
Non-Nordic and unspecified & & 35 & 38 & 41 \\
foreign productions & 34 & 100 & 100 & 100 \\
SUM & 99 & & & \\
\hline
\end{tabular}

Source: NRK annual reports, NRK programunders $\emptyset$ kelsen.

Table 23. TV2. Origin of Programmes. Per Cent of Total Programming

\begin{tabular}{lrrrrr} 
& 1994 & 1995 & 1996 & 1997 & 1998 \\
\hline Norway: own and purchased & 48 & 55 & 52 & 50 & 50 \\
USA & 30 & 32 & 34 & 33 & 31 \\
Australia & 7 & 5 & 5 & 7 & 10 \\
UK & 6 & 4 & 4 & 3 & 3 \\
Sweden and Denmark & 5 & 2 & 3 & 3 & 3 \\
France and Germany & 5 & 3 & 3 & 2 & 1 \\
Other & - & - & - & 3 & 2 \\
SUM & 101 & 101 & 101 & 101 & 100 \\
\hline
\end{tabular}

Source: TV2 Annual report.

Table 24. European Productions. NRK, TV2, TVNorge. Per Cent

\begin{tabular}{lccc} 
& 1996 & 1997 & 1998 \\
\hline NRK1 & 80 & 77 & 80 \\
NRK2 & 64 & 62 & 69 \\
TV2 & 54 & 50 & 51 \\
TVN & 11 & 14 & 13 \\
\hline
\end{tabular}

Source: Norwegian Mass Media Authority (SMF).

Data is not available from TVNorge and TV3. However, a brief survey of the schedules indicates that the proportion of Norwegian and Nordic programmes on these channels is much lower than on TV2 and NRK. Regarding European productions, there are also marked differences between the channels (Table 24).

The data in table 24. are calculated according to EU norms and therefore contain different percentages from the above tables. Nevertheless, the dif- 
ference between the channels is very clear: while TVNorge has a very small share of European programming, TV2 and NRK both had a majority of European productions. Nevertheless, in the case of the private channels, "European" for the most part equals Norwegian. The table confirms the impression that almost all non-Norwegian programming on TV2 and TVNorge come from the US, whereas NRK buys more material from the UK and other European countries. It also confirms that the recommendation of the EU television directive that a majority of programming should be of European origin has no effect on private channels like TVNorge.

\section{Composition of Programming}

The composition of programming is perhaps the best indicator of the differences between channels. In this section we compare the development of the schedules for the national channels over the last years.

NRK made substantial changes in the composition of its schedule in the early 1990s, as a way of preparing itself for the increased competition from TV2. Since then, the proportion of different genres on NRK1 has been relatively stable. In recent years, the most substantial changes are linked with the establishment of NRK2.
An analysis of the total output (Table 25.) shows a stable pattern in the 1990s. There has been an increase in the share of cultural programmes, music, educational programmes and programmes for children and youth, all linked with the establishment of NRK2. So far, there is no firm evidence that NRK1 is developing towards a more entertainment-oriented schedule; NRK1 still transmits sizeable amounts of information and culture. Main changes have nevertheless taken place concerning the composition of programming in prime-time. More and more, prime-time on NRK1 is reserved for mass audience programming, and the share of entertainment has increased (Syvertsen 1997).

TV2's programme statistics are not as complete as NRK's. The general picture, however, is that the distribution between different genres is relatively stable (Table 26).

An analysis of TV2's output show that drama/ fiction is the dominant category and has increased its dominance since 1995 . TV2 has more than three times as much drama as NRK1 and twice as much as NRK2. The proportion of information programmes has also increased, while other programming remains marginal. The share of advertising is not included although this makes up a substantial amount (10-15\%).

The only programme statistics available from TVNorge is based on individual sample weeks in

Table 25. Television Programming. Share of Different Genres NRK1 and NRK2. Per Cent

\begin{tabular}{lrrrrrrr} 
& \multicolumn{9}{c}{ NRK1 } & & \multicolumn{3}{c}{ NRK2 } \\
& 1995 & 1996 & 1997 & 1998 & 1996 & 1997 & 1998 \\
\hline News & 8 & 7 & 8 & 10 & 4 & 5 & 3 \\
Information & 15 & 17 & 20 & 16 & 17 & 14 & 20 \\
Drama & 17 & 16 & 15 & 14 & 24 & 25 & 21 \\
Entertainment & 7 & 6 & 6 & 6 & 1 & 0,3 & 2 \\
Sports & 15 & 20 & 14 & 19 & 2 & 2 & 3 \\
Children/youth & 16 & 19 & 20 & 19 & 12 & 16 & 18 \\
Religion & 2 & 2 & 2 & 2 & 0,2 & 1 & 1 \\
Art/culture/media & 3 & 4 & 4 & 3 & 11 & 14 & 12 \\
Nature/science & 5 & 3 & 2 & 3 & 1 & 1 & 1 \\
Music & 3 & 2 & 2 & 2 & 10 & 9 & 7 \\
Education & 4 & 2 & 2 & 3 & 12 & 6 & 8 \\
Other & 4 & 2 & 5 & 3 & 7 & 6 & 6 \\
SUM & 99 & 100 & 102 & 100 & 101 & 99 & 102
\end{tabular}


Table 26. TV2: Share of Different Genres. Per Cent

\begin{tabular}{lrrrr} 
& 1995 & 1996 & 1997 & 1998 \\
\hline News/weather & 16 & 12 & 10 & 10 \\
Current affairs/debate/ & & & & 13 \\
human interest/breakfast-TV & 11 & 18 & 4 & 5 \\
Documentaries/nature & 5 & 4 & 51 & 49 \\
Drama & 44 & 50 & 6 & 6 \\
Show (entertainment) & 8 & 6 & 7 & 8 \\
Sports & 7 & 3 & 3 & 3 \\
Children & 3 & 0,5 & 2 & 0,6 \\
Religion & 1 & 2 & 1 & 3 \\
Music & 3 & 1 & 99 & 1 \\
Other & 3 & 102 & & 99 \\
SuM & 101 & & 2 &
\end{tabular}

Source: TV2 annual reports.

Table 27. TVNorge: Share of Different Genres. Per Cent

Fall $1996 \quad$ Spring $1996 \quad$ Fall $1997 \quad$ Spring $1997 \quad$ Spring 1999

\begin{tabular}{lrrrrr}
\hline News & 3 & 5 & 4 & 7 & 4 \\
Non-fiction & 14 & 10 & 8 & 1 & 17 \\
Drama, comedy & 67 & 67 & 78 & 75 & 69 \\
Entertainment: own productions & 14 & 16 & 9 & 11 & 8 \\
Sports & 2 & 2 & 1 & 6 & 2 \\
SUM & 100 & 100 & 100 & 100 & 100 \\
\hline
\end{tabular}

Source: TVNorge research. The data are from individual sample weeks in the high season.

Table 28. TV3: Share of Different Genres. Per Cent

1997

Purchased films, series, sitcoms

Purchased talk shows

Children

Sports

Own productions

TV-shop

SUM

Source: TV3 research.

the high season (Table 27). The categories are different from NRK and TV2.

Since the statistics only covers a short period it is meaningless to talk about trends in TVNorge's case. It is nevertheless worth mentioning that TVNorge went through major programming reforms in 1995 and 1996 and that further changes were made in the wake of the joint agreement with 
TV2. TV2's strategy for TVNorge was that the latter channel should appeal more to younger viewers and be more of an entertainment channel, whereas TV2 should focus more on news, current affairs and family programming.

The only statistics available from TV 3 cover 1997 and 1998 (Table 28).

\section{Summary and Comparisons}

The most prominent difference between the channels concerns the proportion of fiction/drama. On TVNorge and TV3, channels with no public service obligations, more than $70 \%$ of the total output consist of fiction. On TV2 the figure is slightly above $50 \%$, whereas on NRK the proportion is less than $20 \%$.

The amount of factual programming varies correspondingly. NRK and TV2 each make a much more substantial contribution than TV3 and TVNorge within the genres of news, information, documentaries and science/nature programmes. These genres are crucial for the understanding of TV2 and NRK as public service channels with an obligation to sustain an informed democracy. These genres also carry substantial costs compared with bought-in packages of talk shows, drama series and home shopping which dominates on TVNorge and TV3. TV3 has no news at all and very little information. TVNorge has a proportion of news and information, but much less than TV2 and NRK.

A third difference between the channels lies in the fact that NRK has a far more substantial output of music, religion, culture and education than any other channel. Indeed, NRK is more or less the only channel to have any programming at all within these genres. Thus, it is clear that the NRK feels a special responsibility for the "classic public service genres" which no other broadcasters take seriously. As previously indicated, such programming is also transmitted in the evenings.

A fourth difference worth noting that NRK transmits a much higher share of sports than any other channel. Indeed, comparative statistics produced by Nordicom (1999) indicates that NRK1 has more than double the amount of sports programming than almost all other Nordic channels.

Finally, NRK and TV3 are the two channels to have the most substantial output of children's programmes. TV2 has a much smaller share, whereas TVNorge has no children/youth programmes at all. This difference can be explained with reference to the fact that TV3 operates from London and is the only channel which legally can transmit advertising directed at children and advertising in connection with children's programmes. TV3 has nevertheless a much smaller proportion of children/youth programming than NRK.

The differences between the channels outlined here are related to crucial organisational features. NRK has a large production apparatus and a large, permanently employed, workforce, who are constantly developing new programmes and programme formats. Consequently, the NRK schedule is varied compared to all other channels, and new programme series are constantly launched. NRK produces most of its programming in-house and, apart from the general "inspiration" drawn from channels in other countries, rarely purchases standardised formats. Compared with other channels, NRK1 and 2 has a far larger share of programmes with minority appeal. In its Norwegian produced programming, NRK is by far the most innovative and experimental of the Norwegian services. NRK is the only operator to have a substantial television production at the regional level and its own regional television services.

TV2 is clearly in a position between the NRK and other private channels. TV2 is dependent on external producers for most of its programming, and have a preference for long series. TV2 rely much more on purchased and adapted formats than NRK, particularly within entertainment. Generally, TV2 has very few programmes with minority appeal, almost all the output is designed to draw large audiences and there are no provisions for cultural or ethnic minorities (even if TV2 is legally obliged to have such provisions). The output is generally mainstream, but TV2 can still be said to be innovative in some of its information and fiction programmes. For example, TV2 has recently put more effort into developing its own, journalism-based, adventure/entertainment formats. These differ from the traditional studio-based entertainment formats of NRK.

TVNorge's and TV3's programmes are different from NRK's, and also, in some respects, different from TV2's. Like TV2, TVNorge and TV3 prefer longer series, simple formats and formats which are purchased and/or adapted from other channels. Still, their output is far more mainstream than that of TV2. Compared with TV2, TVNorge and TV3 have very little home-produced programming, few innovative formats, hardly any information programmes and no programmes which are designed to appeal to smaller groups of viewers. 


\section{Trends and Issues: the Digital Future}

The aim of the report has been to outline the features of the Norwegian television market as it has developed throughout the 1990s. The report has demonstrated that this market, in many respects, is a rather stable one: the traditional public service broadcaster NRK retains a dominant position and it is the generalist channels of NRK1 and TV2 that command most of the resources. These channels are also leading programme providers in the sense that they are the only channels to offer a substantial and varied output of domestic and foreign programming. The study has nevertheless shown that there are some indications that the era of duopoly, characterised by stable competition between two public service channels of which one is funded through licence fees and one through advertising, may be coming to an end. One indication is that specialised and foreign channels are increasing their share of the viewing time, another is that it's becoming more difficult for the national operators to secure the rights they need in order to sustain their position. All this takes place in an atmosphere where there is a growing uncertainty about the future of broadcast television as a whole. The main issue in the current debate is, in Norway as elsewhere: What will be the role of traditional terrestrial broadcasting in the face of digitisation and related technological and economic developments?

One company has started digital broadcasting in Norway. Canal Digital Norway launched their digital broadcasting by satellite autumn 1998. Canal Digital's digital television package offers subscribers about 20 digital music channels, pay-per-view film channels, special broadcasts from major sports events and also NRK1\&2, TV2 and TVNorge. In addition to selling digital receiving equipment, $\mathrm{Ca}$ nal Digital Norway also has such systems for rent. This is not a lucrative business in itself, but the company does this in order to speed up the process of adaptation among consumers (http://w3.digi.no/ digi98.nsf/pub/md79292341hb6606546120 sept. 99). In July 1999, there were a total of 25000 systems for receiving digital satellite broadcasts in Norway.

Viasat, the other pay-TV service directed towards Norwegian customers, has not yet announced when they will begin their digital transmissions. According to Managing Director Peder Ramel, Viasat can be ready to start digital transmission six months after the decision is reached. In the meantime, Viasat has complained to the Competition
Authorities about the agreement between TV2 and Canal Digital, which gave Canal Digital Norway an exclusive right to satellite distribution of TV2. After NRK, TV2 and TVNorge signed up with Canal Digital for digital satellite distribution, Viasat/TV3 is the only real competitor in the Norwegian market, and in the Viasat package, TV3 is the only generalist Norwegian channel. The Competition Authorities has consequently prohibited the agreement between Canal Digital and TV2. The deal between NRK and Canal Digital is legal because it is non-exclusive. NRK might well sign up with other operators in the future.

Thus, both NRK and TV2 are already available on digital satellite services. While TV2 seems content with a wait-and-see approach for the time being, NRK, for its part, has lobbied for several years in favour of a terrestrial digital net. This has been successful to some extent, as a Government White Paper in June 1999 proposed that two terrestrial distribution networks be established. The proposed networks would have a capacity of eight channels and additional services. In the long term, more channels and services could be made available. The main argument for a terrestrial solution is that this would be the best way to secure the whole population access to relatively inexpensive services based on Norwegian reality and culture (St. meld. 46 1998/99). But there are many problems which are not yet solved. The question of funding is one of the most important ones: The White Paper proposes that no state funding should be available, but that the state should retain the role of licensing authority. Another question is how one should get the part of the population who has a choice, to connect to a terrestrial network, rather than signing up for a satellite or cable solution which would grant them a much more extensive output.

NRK has declared that it wishes to utilise capacity corresponding to four national channels in a potential terrestrial network. This is, however, on the condition that funds are made available in order to ease the transition from analogue to digital broadcasting. NRK has asked the Ministry of Culture for a special grant of 1.9 billion NOK over 1015 years in order to cover the extra costs involved with parallel broadcasts. In order to meet the obligation to cover the whole population, NRK will have to transmit through both digital and analogue distribution networks until a sufficient number of consumers have gone digital and the analogue network may be "turned off". Extra funds are also necessary in order to convert material from the ar- 
chives into the digital format, and develop new programming that can make the digital services attractive to consumers.

So far, there are several questions that must be solved for digital television to get off the ground in Norway. One of the major issues regards standardisation: while a common standard has been established for digital transmissions, common standards have not yet been established for digital reception. In this situation, Nordic broadcasters agreed in 1997 that they would work toward a common standard for the set top boxes necessary to receive digital television. They are also considering the development of a common Nordic pay-TV channel based predominantly on the programme archives of the public broadcasters (NorDig).

\section{Sources \\ Interviews}

Gudvind Berger, Chief Accountant, NRK (10.07.98)

Åke Källquist, Editor of Purchases, Drama, NRK (06.07. 98)

Kjersti Nordtveit, Director of Finance, NRK (18.05.98)

Alf Kristian Nordberg, Controller, NRK (30.06.98, 6.8.98)

Hanne Løchstøer, Head of Information, NRK (29.06.98)

Arne Wam, Managing Director, NRK Aktivum (25.06.98)

Gro Skjensvold, Director of Finance, NRK-TV (6.8.98)

Nils Ketil Andresen, Programme Editor, TV2 (01.07.98)

Øivind Johannessen, Director of Finance, TV2 (18.05.98)

Pål Veiby, Head of projects, TV3 (10.07.98)

Morten Skotland Hansen, Chief Financial Officer, TvNorge (25.05.98)

Espen Asheim, Managing Director, Canal Digital Norge (25.05.98)

Jørgen Klafstad, Managing Director, Canal+ (20.8.98)

Einar Brustad, Managing Director, Viasat Norge (18.06.98)

Erik Langebekk, Adviser, Norwegian Mass Media Authority (19.06.98)

Kjetil Klunderud, First Clerical Officer, Ministry of Culture (27.04.98)

Odd Gustu, Head of Marketing, Tono (Right holders) (06.07.98)

\section{Documents and regulations}

EU Television Directive: 89/552/EEC and 97/36/EC.

Allmennkringkastingsrådet (Public Service Council) Performance Reviews 1996, 1997.

Kringkastingsloven (Broadcasting Act): Lov av 4. des. 1992 nr 127 om kringkasting.

Forskrift om kringkasting, 1998 (Supplementary regulations).
Finally, it is worth emphasising that the Norwegian telecom, Telenor, is a major actor in the satellite business. Through its satellite Thor II (launched in 1998), the transmission capacity for the satellite position at 1 degree west (the position most Norwegian dishes are adjusted to) increased to 130 channels. Telenor also has control over the terrestrial transmission network through the company Norkring (which it owns jointly with the NRK). Thus, Telenor is both an ally and a competitor to the broadcasting corporations, indicating that the process of convergence between broadcasting and telecommunication is already well underway.

Konkurransetilsynets vedtak (Competition Authority Ruling) 20.10.97.

Lov om tilsyn med erverv i dagspresse og kringkasting.

Ot.prp. nr. 55 (1989-90) TV2. Lov om reklame i kringkasting m.v.

Ot.prp. nr. 69 (1994-95) Norsk rikskringkasting som aksjeselskap.

St.meld. nr. 46 (1994-95) Tilleggskanal for NRKFjernsynet m.v

St.meld. nr. 32 (1992-93) Media i tida.

St.meld. nr. 42 (1993-94) Kringkasting og dagspresse 1993 m.v.

St.meld. nr. 18 (1995-96) Kringkasting og dagspresse 1994 m.v.

St.meld. nr. 12 (1996-97) Kringkasting og dagspresse 1995 m.v.

St.meld. nr. 62 (1996-97) Kringkasting og dagspresse 1996 m.v.

St.meld. nr. 12 (1998-99) Kringkasting og dagspresse $1997 \mathrm{mv}$

St. meld. nr. 46 (1998/99) Digitalt fjernsyn.

St.prop. nr. 1 Statsbudsjettet medregnet folketrygden 1994 95, 1995-96, 1996-97. B. Innst.S. nr.2 1996-97.

NRK vedtekter (NRK regulations).

NRK programregler (Principles for programming).

NRK Annual reports 1993-97.

NRK Public service account 1996-1997.

NRK newsletter.

TV2 konsesjonsavtale (TV2 licence agreement).

TV2 annual reports 1993-97.

\section{Statistical sources}

Carat Norway

GRAMO 
Norsk Gallup Institutt, Norway.

Norwegian Mass Media Authority (SMF).

NRK programundersøkelser.

NRK Tall og fakta.

Markeds- og mediainstituttet/Norsk TV-meter panel.

Media Trends 1997 in Denmark, Finland, Iceland, Norway and Sweden (1998) Nordic Media Trends, 3. Göteborg: Nordicom (edited by Ulla Carlsson and Eva Harrie).

Nordic Baltic Media Statistics 1998 (1999) Nordic Media Trends, 4. Göteborg: Nordicom (edited by Ulla Carlsson and Eva Harrie).

Mediebyråenes Interesseorganisasjon.

Reklamebyråforeningen.

Statistics Norway: Statistical Yearbook.

TV3 Research.

TVNorge Research.
An excellent statistical source for Norwegian media data is Medienorge: http://medienorge.uib.no/

\section{Other references}

Futsæter, (1998) "Fragmentering av medielandskapet og oppsplitting av publikum". Norsk medietidskrift, 1/ 98.

Syvertsen, Trine (1997) Den store TV-krigen - Norsk allmennfjernsyn 1988-96. Bergen: Fagbokforlaget.

Syvertsen, Trine (1992) Public Television in Transition: A Historical and Comparative Analysis of the BBC and the NRK. Thesis submitted for the degree of Doctor of Philosophy at the University of Leicester. Levende Bilder 5/92. Oslo: KULT/ NAVF. 